\title{
Maternal seafood diet, methylmercury exposure, and neonatal neurologic function
}

\section{Citation}

Steuerwald, Ulrike, Pal Weihe, Poul J. Jørgensen, Kristian Bjerve, John Brock, Birger Heinzow, Esben Budtz-Jørgensen, and Philippe Grandjean. 2000. "Maternal Seafood Diet, Methylmercury Exposure, and Neonatal Neurologic Function." The Journal of Pediatrics 136 (5) (May): 599-605. doi:10.1067/mpd.2000.102774.

\section{Published Version}

doi: $10.1067 / \mathrm{mpd} .2000 .102774$

\section{Permanent link}

http://nrs.harvard.edu/urn-3:HUL.InstRepos:34787288

\section{Terms of Use}

This article was downloaded from Harvard University's DASH repository, and is made available under the terms and conditions applicable to Other Posted Material, as set forth at http:// nrs.harvard.edu/urn-3:HUL.InstRepos:dash.current.terms-of-use\#LAA

\section{Share Your Story}

The Harvard community has made this article openly available.

Please share how this access benefits you. Submit a story.

\section{Accessibility}


Manuscript submitted to Journal of Pediatrics (revised)

\section{Maternal seafood diet, methylmercury exposure, and neonatal neurological function}

Ulrike Steuerwald, MD, Pal Weihe, MD, Poul J. Jørgensen, MEng, Kristian Bjerve, MD, John Brock, PhD, Birger Heinzow, MD, Esben Budtz-Jørgensen, MS, Philippe Grandjean, MD, PhD

From the Faroese Hospital System, Tórshavn, Faroe Islands; the Institutes of Public Health and

Clinical Research, Odense University, Odense, Denmark; the Department of Clinical Chemistry, Trondheim University, Norway; the National Center for Environmental Health, Centers for Disease Control and Prevention, Atlanta; the State Agency for Nature and Environment, Schleswig-Holstein, Flintbek, Germany; the Department of Biostatistics, Panum Institute, University of Copenhagen, Copenhagen, Denmark; and the Departments of Environmental Health and Neurology, Boston University Schools of Medicine and Public Health, Boston.

Supported by grants from the European Commission (Environment and Climate Research Programme, EV 5V-CT940472), the U.S. National Institute of Environmental Health Sciences (ES06894), and the Danish Medical Research Council.

Correspondence to: Philippe Grandjean, Institute of Public Health, Odense University, Winsløwparken 17, 5000 Odense C, Denmark. Phone: +45-65573768. Fax: +45-65911458.

Email: p.grandjean@winsloew.ou.dk

Key words: Environmental pollution Food contamination Methylmercury compounds Polychlorinated biphenyls Prenatal exposure delayed effects 


\begin{abstract}
Objective: To determine whether neonatal neurological function is adversely affected by seafood contaminants from maternal diet during pregnancy.

Study design: A cohort of 182 singleton term births was established in the Faroe Islands, where marine food includes pilot whale. Maternal serum, hair, and milk, and umbilical cord blood were analyzed for contaminants. Essential fatty acids, selenium, and thyroid function parameters were determined in cord blood. The infant's neurological optimality score was determined at two weeks of age adjusted for gestational age, and predictors were assessed by regression analysis.

Results: Exposures to methylmercury and polychlorinated biphenyls were increased in relation to maternal seafood intake, as were $\omega 3$ fatty acid concentrations in cord serum. Thyroid function showed no abnormalities. After adjustment for confounders, a 10-fold increase of the cord-blood mercury concentration was associated a decreased neurological optimality score of $2.0(p=0.03)$. This effect corresponds to the one caused by a decrease in gestational age of about three weeks. Other seafood diet parameters had no effect on this outcome.

Conclusions: Prenatal exposure to methylmercury from contaminated seafood was associated with an increased risk of neurodevelopmental deficit. Thus, in this North Atlantic population, methylmercury constituted an important neurological risk factor, while effects of other seafood components were not detectable.
\end{abstract}


Steuerwald et al.

\author{
Abbreviations: \\ DDE: dichlorodiphenyldichloroethene \\ DDT: dichlorodiphenyltrichloroethane \\ DHA: docosahexaenoic acid \\ EPA: eicosapentaenoic acid \\ NOS: neurological optimality score \\ PCB: polychlorinated biphenyl \\ $\Sigma$ PCB: sum of polychlorinated biphenyl congeners
}




\section{Steuerwald et al.}

Methylmercury is a seafood contaminant which has raised concern regarding the safety for pregnant women (1). Seafood seriously contaminated with methylmercury in Minamata, Japan, caused many cases of a congenital poisoning that, at first, resembled spastic paresis (2). In a later incident in Iraq, an increased number of neurological abnormalities was observed in infants when the maternal hair-mercury concentration had exceeded approximately $10 \mu \mathrm{g} / \mathrm{g}(50 \mathrm{nmol} / \mathrm{g})(1,3)$. Prenatal exposures below this level were associated with neurobehavio delays detectable at age seven years (4), but equivocal findings on developmental tests have been reported from other studies of younger children $(5,6)$. Other seafood contaminants include polychlorinated biphenyls (PCBs), a prenatal PCB exposures have also been linked to delays in neurobehavioral development (7-9). However, the nature of these deficits and their detailed relation to specific organochlorine compounds is unclear, although som PCBs may act via interference with thyroid function (10).

Major essential nutrients in seafood include $\omega 3$ polyunsaturated fatty acids (11) and selenium (12). Essential fatty acids are necessary for optimal neurological development (13), and they could potentially modify the effects of neurotoxicants (14). In experimental models, selenium in seafood may attenuate methylmercury toxicity (15). Thus, seafood diets during pregnancy must be considered as a balance between the beneficial effec of essential nutrients and the adverse effects caused by toxicants.

We have examined these issues in the Faroe Islands, a North Atlantic fishing community of about 42,00 inhabitants, where the marine diet may also include pilot whale meat and blubber. Whale meat contains increase mercury concentrations, and blubber has a high PCB content, thus contributing to neurotoxicant exposures (4). T lipid phase of marine fish often contains about 10-15\% eicosapentaenoic acid (C20:5 docosahexaenoic acid (C22:6 13 , DHA) (11), while pilot whale blubber contains somewhat lower levels of these two $\omega 3$ polyunsaturated fatty acids (Marita Poulsen, pers. comm.). Apart from lamb, potatoes and some dairy 


\section{Steuerwald et al.}

products, the majority of the Faroese food is otherwise imported from other countries, and the lifestyle is Scandinavian.

\section{Methods}

Cohort Establishment

During a 12-month period in 1994-1995, a cohort of 182 singleton term births was generated from consecutive births at the National Hospital in Tórshavn, Faroe Islands. Maternal residence was required in the central and northwestern region of the primary catchment area, i.e., away from the capital area of Tórshavn. Abo one-third of the Faroese population resides in this area, where the mercury exposure was expected to vary the mc About $64 \%$ of all births were included, incomplete sampling being mainly due to logistic problems in the busy ward. In addition, four children were excluded because they were born before the 36th week of gestation, and tw children because they had congenital neurological disease; none of the children had a birth weight below $2500 \mathrm{~g}$. The overall participation rate is slightly below the one obtained in a previous Faroese cohort (4), but the average birth weight was almost the same in the two cohorts and similar to the Faroese average. Relevant obstetric data were obtained by standardized procedures $(16)$ and supplemented by a brief nutrition questionnaire $(4,17)$. The study design and methodology were approved by the Faroese Ethical Review Committee. The main characteristi of the cohort are shown in Table I.

Maternal serum was obtained in connection with the last antenatal consultation at week 34 . Blood from the umbilical cord was taken by the midwife in heparinized syringes with teflon-lined pistons. In connection witl the parturition, a hair sample of at least $100 \mathrm{mg}$ was cut with a pair of scissors close to the root in the occipital ar of the mother. Transition milk was obtained at days 4 or 5 after parturition. 


\section{Steuerwald et al.}

\section{Outcome Measures}

For the neurological examination of the newborn infant, the technique described by Prechtl (18) was us at approximately two weeks of age adjusted for gestational age. This schedule includes items to assess functiona abilities, most reflexes and responses, as well as the stability of behavioral status during the examination. All iter are classified as clinically optimal, questionable, or suboptimal. The neurological optimality score (NOS) is the number of main items rated optimal (out of 60). Also, two subscores are formed, one for muscle tone and one for reflexes. This highly standardized test has a substantial degree of predictive validity (19). The examiner had trair in Groningen, the Netherlands, under supervision by Professor Bert Touwen; the NOS scores were also calculate in Groningen. Examiner and scorer were blinded with regard to exposure variables.

Thyroid stimulating hormone was measured in maternal serum and in cord serum by a time-resolved fluoroimmuno assay, and thyroxin and resin-triiodothyronine uptake were determined by radioimmuno assay. Fr thyroxin and free triiodothyronine were measured by the radioimmuno assay after dialysis to equilibrium. Exposure Biomarkers

Mercury analysis: Maternal hair (the first $3 \mathrm{~cm}$ from the root), and cord whole-blood and serum were analyzed in duplicate by flow-injection cold-vapor atomic absorption spectrometry after digestion of the sample a microwave oven $(4,20)$. Mercury results in $\mu \mathrm{g}$ may be converted to nmol by multiplying by 5.0 .

Serum organochlorine analysis: Two milliliters of all maternal serum samples and $10 \%$ of the cord-seru samples were analyzed at the National Center for Environmental Health at CDC in Atlanta (21): Eighteen parent pesticides or their metabolites and twenty-eight persistent PCB congeners were quantified by a two-stage solid- 


\section{Steuerwald et al.}

phase extraction method followed by gas chromatography analysis with electron capture detection. The results were adjusted for total serum lipid content and reported as ng/g lipid. The limit of detection varied from $0.08 \mathrm{ng} /$ to $0.66 \mathrm{ng} / \mathrm{ml}$. For maternal serum with an average lipid content of about $9 \mathrm{~g} / \mathrm{l}$, these limits correspond to $9 \mathrm{ng} / \mathrm{g}$ and $70 \mathrm{ng} / \mathrm{g}$ lipid.

Milk organochlorine analysis: As an additional measure of perinatal exposure, $5 \mathrm{ml}$ of human milk were analyzed at the Institute of Environmental Toxicology, Kiel, Germany (22) for a similar array of organochlorine compounds. Following solid-liquid-phase extraction, analyses were performed by gas chromatography with electron capture detection. At a 5\% fat content, the detection limits were 2 and $5 \mathrm{ng} / \mathrm{g}$ lipid for pesticides and PCBs, respectively.

Selenium analysis: Selenium in cord whole-blood was determined by electrothermal atomic absorption spectrometry with Zeeman background correction (23). Selenium results in $\mu g$ may be converted to umol by dividing by 79 .

Fatty acid analysis: Cord-serum phospholipids were extracted and transmethylated before analysis on a gas chromatograph with a flame ionization detector (24). All results were reported as relative concentrations in percent of total phospholipid fatty acids.

\section{Data Analysis}

Parameters which deviated substantially from a Gaussian distribution, especially the exposure biomarkers, were normalized by logarithmic transformation. For some organochlorine results, transformations and calculation of geometric means and correlation coefficients were performed with the actual measured values even when they were below the detection limit. Parametric methods were used whenever applicable. However, the dietary 


\section{Steuerwald et al.}

questionnaire data required the use of Spearman's correlation coefficient $\left(\mathrm{r}_{\mathrm{s}}\right)$. Regression analyses were carried o with the NOS as the dependent variable and with potential predictors selected a priori. Individual exposure parameters were then entered as continuous variables, using covariates that were significant at $\mathrm{p}<0.1$ for confounder adjustment. For the sake of uniformity, two-tailed p-values were used.

\section{RESULTS}

The questionnaire data regarding dietary habits during pregnancy confirmed that this population is high dependent on seafood, including pilot whale; summary data are shown in Table I. Most of the pregnant women were nonsmokers, with only $19(10.4 \%)$ smoking more than 10 cigarettes per day. Likewise, only 5 women $\left(2.7^{\circ}\right.$ drank alcoholic beverages at least once per month during pregnancy. Six mothers (3.3\%) were less than 18 years

The average mercury exposure was elevated, but varied widely (Table II). Fifteen hair samples (10.4\%) exceeded a mercury concentration limit of $10 \mu \mathrm{g} / \mathrm{g}(50 \mathrm{nmol} / \mathrm{g})$. The three mercury exposure biomarkers were highly interrelated, with correlation coefficients of 0.76-0.82 after logarithmic transformation. Exposures to organochlorine compounds were also increased (Table II). The $\Sigma$ PCB concentration was calculated as 2.0 times 1 sum of the most prevalent congeners 138, 153 and 180 (IUPAC numbers) (25). Lipid-based concentrations of the same analyte in serum and milk correlated well, but were generally higher in milk. The lipid-based $\Sigma$ PCB concentrations in the 19 cord serum samples were similar to those in maternal serum $(r=0.97)$. However, volum based serum concentrations correlated less well and reflected the 3-to-4-fold difference in lipid content (means, 2 $\mathrm{g} / 1$ and $9.0 \mathrm{~g} / \mathrm{l}$ in cord and maternal serum, respectively). Other organochlorine compounds in the same sample correlated well with $\Sigma \mathrm{PCB}$ and $p, p^{\prime}$-DDE.

The frequency of whale meat dinners was the best predictor for the mercury concentrations, while the 


\section{Steuerwald et al.}

frequency of blubber dinners during pregnancy was the best predictor for the organochlorine concentrations (Tab II). The $\Sigma \mathrm{PCB}$ concentration in maternal serum correlated significantly with mercury concentrations in maternal hair and cord blood ( $\mathrm{r}=0.53$ and 0.43 , respectively).

Maternal seafood intake was also associated with increased concentrations of $\omega 3$ fatty acids and seleniu in cord blood (Table III). EPA and selenium concentrations also showed highly significant associations with the seafood contaminants.

Thyroid function parameters revealed no clear association with contaminant concentrations, except that the resin-triiodothyronine uptake in cord serum seemed to decrease at increasing $\Sigma \mathrm{PCB}$ concentrations $(\mathrm{r}=-0.21$ $=0.01)$. The thyroid stimulating hormone concentration in cord blood and maternal serum showed a weak negati association with $\Sigma \mathrm{PCB}(\mathrm{r}=-0.04 ; \mathrm{p}=0.66$; and $\mathrm{r}=-0.13 ; \mathrm{p}=0.09)$.

The infants had an average NOS of 49.8, with $77(43.8 \%)$ below 50 . The score was significantly associated with gestational age, but not with birth weight. Maternal age, parity and education were not associatec with the NOS. Diabetes mellitus or signs of gestational diabetes $(\mathrm{N}=11)$ were associated with a higher birth weight, a shorter gestation and, at the same time, a lower NOS $(p=0.001)$. The average NOS score was higher it girls $(50.5 \pm 4.1)$ than in boys $(49.1 \pm 4.8)(\mathrm{p}=0.04)$. Other potential risk factors recorded as part of the obstetric optimality schedule (24) were not associated with a decreased NOS.

The cord-blood mercury concentration showed a negative association with the NOS, and results for quartile exposure groups are shown in Fig. 1 . The unadjusted regression coefficient was $-2.0(p=0.03)$. Thus, a 10-fold increase in mercury was associated with a NOS decrease of 2 . After confounder adjustment and exclusio of the 11 children of diabetic mothers, the adjusted coefficient was nearly unchanged $(-2.1 ; p=0.03)$. A shorten of gestational age by 3 weeks was associated with a decrease in NOS similar to the one related to a 10 -fold incre 


\section{Steuerwald et al.}

in mercury exposure. The mercury/selenium ratio showed only a slightly improved association with the outcome variable. Removal of the child with the lowest NOS (the most influential observation) also had only a small effec on these associations. The mercury concentration in cord serum was also a significant predictor in the regression analyses, while the maternal hair concentration was not.

Concentrations of $\Sigma \mathrm{PCB}$ and $p, p$ '-DDE showed weak, positive associations with the NOS (Table II), an adjustment for covariates and mercury exposure caused only minor changes. The fatty acids (Table III) and thyrc parameters were also poorly associated with the overall NOS, and no clear association with dietary questionnair parameters was found. Adjustment for $\Sigma$ PCB and $\omega 3$ fatty acid concentrations also did not have a discernible eff on the mercury regression coefficient.

The NOS subscores for muscle tone and reflexes showed no clear associations with any of the risk indicators studied. A review of individual tasks showed no clear pattern, except that slight or marked opisthotonı was present in 20 infants and absent in 157 infants (geometric means of cord-blood mercury concentrations, 34.3 $\mu \mathrm{g} / \mathrm{l}$ and $19.5 \mu \mathrm{g} / \mathrm{l} ; \mathrm{p}=0.005)$.

\section{DISCUSSION}

In the present study, increased exposures to methylmercury from maternal seafood intake were associat with a significant decrease in the neonatal neurological optimality score (Fig. 1). Methylmercury is a well documented developmental neurotoxicant $(1,2,4)$, but neonatal function was not examined in previous cohort studies $(4,6)$. Although previous studies have linked prenatal exposure to PCBs and other organochlorine compounds to neurotoxic effects in children (7-9), PCBs had no discernible effect on neurological function in th present study. 


\section{Steuerwald et al.}

The neonatal neurodevelopmental scale used in this study has been developed to ascertain the integrity the neonatal nervous system in a reproducible way (18). The NOS has been useful in epidemiological studies to determine subsequent risks for major or minor neurological dysfunctions (19). Recently, the Dutch researchers ( reported that a decreased neonatal NOS was associated with biomarkers of increased dioxin exposure, and PCB congeners showed a significant association with a decreased muscle tone score. While the same outcome parame was used in the Faroes, the different outcomes of these studies must be interpreted in the light of the exposure settings.

The average mercury concentrations (Table II) are similar to those seen in a previous Faroese cohort stu $(4,17)$. The cord-blood mercury concentration indicates the amount of methylmercury that has reached the fetal circulation. The maternal hair concentration may be a less precise risk indicator $(4,26)$. Sources of imprecision fo hair-mercury concentrations include external contamination during hair growth (27), and studies that have relied solely on maternal hair-mercury concentrations $(5,6)$ may therefore involve exposure misclassification. Although mercury exposure levels have not been reported from the Dutch study, they are likely to be similar to those seen populations that eat seafood infrequently $(1,23)$, i.e., with averages of about one-tenth of those seen in the Faroes Because even small increases in methylmercury exposure may be associated with a decreased neonatal NOS (Fig.1), an undetected mercury effect in the Dutch study cannot be ruled out.

The milk PCB concentrations are similar to results from Faroese samples collected in 1987, where the overall average for four pooled samples was slightly above $2 \mu \mathrm{g} / \mathrm{g}$ lipid (25). Simlarly, $\Sigma$ PCB in cord tissue from the same cohort (4) showed an arithmetic average of $1.6 \mathrm{ng} / \mathrm{g}$ lipid, as calculated from concentrations of congene 138, 153 and 180. However, the Dutch study showed a median of $2 \mu \mathrm{g} / 1$ for the sum of PCB congeners 118,138 , 153 , and 180 in maternal plasma $(9,28)$. In the present study, the median for the same congeners in maternal seru 


\section{Steuerwald et al.}

was $0.64 \mu \mathrm{g} / \mathrm{g}$ lipid; with an average lipid concentration of $9 \mathrm{~g} / \mathrm{l}$, this concentration corresponds to $5.8 \mathrm{ng} / \mathrm{l}$ serum i.e., about 3-fold higher than the average in the Dutch cohort.

The power of a study with regard to separating effects of different components of a complex exposure depends on the association between those components. In the Faroe Islands, methylmercury exposure mainly originates from pilot whale meat, while organochlorine exposure predominantly comes from whale blubber (4). The scattered correlation between mercury and PCB exposure parameters mirrors the one previously reported between cord-blood mercury and cord tissue PCB (4) and suggests that the Faroese are unlikely to eat equal proportions of whale meat and blubber. Although confounding between mercury and PCB may therefore be limited, unmeasured pollutants must also be considered, e.g., dioxins and related compounds. Exposures to these compounds are probably not elevated in the Faroes, as analyses of milk samples from 1987 (25) showed total dioxin equivalent exposure levels similar to the average reported from the Dutch cohorts generated in 1990-1992 (9). However, as increasing dioxin equivalent concentrations in human milk were associated with a lower NOS i the Dutch study, the question should be considered whether a dioxin effect on NOS could explain the mercury association observed (Fig. 1). If that were to be true, then the dioxin exposure level would have to be more close associated with the mercury concentration in cord blood than with the PCB concentration. That possibility woulc appear to be rather remote. Further, while thyroid function data may offer an independent indication of possible organochlorine effects $(10,28)$, the results of the present study were within expected ranges and failed to show a clear association with PCB exposure.

The validity of the NOS assessment must also be critically considered. The NOS results of the present study are lower than those obtained in the Netherlands. Significant differences also occurred between two Dutch centers and were attributed to observer differences (28). Thus, while such differences may be unavoidable, the fa 


\section{Steuerwald et al.}

that all Faroese children were examined by the same pediatrician who was blinded with regard to exposure parameters, offers confidence that the results are unbiased. Under controlled circumstances, the NOS may theref possess sufficient sensitivity, precision, and predictive validity to reveal subtle contaminant-associated neurobehavioral deficits in population studies. Other developmental tests used in young children have shown equivocal associations with hair-mercury concentrations $(5,6)$, perhaps affected both by imprecise exposure assessment and by uncertain validity of response assessments in different cultures. More detailed neuropsychological tests that can be applied at school age have revealed mercury-associated deficits in several domains of brain function (4).

Essential fatty acids from seafood may contribute certain advantages to the infant (13) and may perhaps counteract or protect against adverse effects (14). In agreement with previous studies in adults (29), especially E] showed a clear association with seafood intake (Table III). Analyses in the Netherlands of relative concentrations in cord serum (30) have shown similar averages for arachidonic acid, while those for DHA were about one-half c the level seen in the present study (Table III). These findings emphasize the high average Faroese intake of $\omega 3 \mathrm{fa}$ acids from seafood. Although associated with increased neurotoxicant exposures (Table III), the ample supply of essential nutrients did not provide any detectable beneficial or protective effect on the NOS.

The increased selenium concentrations (Table III) are in accordance with the previous study in the Faro (17), which showed an overall median of $110 \mu \mathrm{g} / \mathrm{l}(1.40 \mu \mathrm{mol} / \mathrm{l})$. These levels are higher than those seen in populations not dependent on marine food (23). Although selenium was present in cord blood in an average mole excess of about 10-fold above methylmercury, no evidence was found that it offered any important protection against a mercury-associated decrease in the NOS.

Because the neurotoxicant may readily pass the placenta, and because the fetal brain must be regarded 


\section{Steuerwald et al.}

particularly sensitively to neurotoxicant exposures and endocrine disruption, safety considerations for contaminated seafood must focus on early development. The present study examined several potentially benefici and detrimental factors, thus allowing a detailed assessment of possible confounding. The detailed assessment of neonatal neurological function showed a negative association only with the cord-blood mercury concentration. $\mathrm{T}$ seafood contaminant therefore deserves increased attention.

We are indebted to members of the Faroese health care system for assistance in generating this cohort and in conducting the examinations of the children, to Brita Andersen and Sylvia Nome Kvam for laboratory assistance and to Dr. Nynke Weisglas-Kuperus and Professor Pieter Sauer (Erasmus University, Rotterdam), Dr. Caren Lanting, Professor Rudi Boersma, and Professor Bert Touwen (University of Groningen) and to Jens Walkowiak and Professor Gerhard Winneke (University of Düsseldorf) for sharing unpublished information and for assistan in coordination and quality assurance. This study is part of the European project on 'Neonatal PCB Exposure anc Neurodevelopmental Deficit' coordinated by Dr. Winneke. 


\section{Steuerwald et al.}

\section{REFERENCES}

1. EPA. Mercury Study Report to Congress. Washington, DC: U.S. Environmental Protection Agency, 1997.

2. Harada M. Minamata disease: methylmercury poisoning in Japan caused by environmental pollution. Crit R Toxicol 1995; 25: 1-24.

3. Marsh DO, Myers GJ, Clarkson TW, Amin-Zaki L, Tikriti S, Majeed M. Fetal methylmercury poisoning: clinical and pathological features. Ann Neurol 1990; 7: 348-53.

4. Grandjean P, Weihe P, White RF, Debes F, Araki S, Murata K, et al. Cognitive deficit in 7-year-old childrer with prenatal exposure to methylmercury. Neurotoxicol Teratol 1997; 19: 417-28.

5. Kjellström T, Kennedy P, Wallis S, Mantell C. Physical and mental development of children with prenatal exposure to mercury from fish. Stage 1. Preliminary tests at age 4. (Report 3080). Stockholm: National Swedish Environmental Protection Board, 1986.

6. Davidson PW, Myers G, Cox C, Shamlaye CF, Marsh DO, Tanner MA, et al. Longitudinal neurodevelopmental study of Seychellois children following in utero exposure to methylmercury from a maternal fish ingestion: outcomes at 19 and 29 months. Neurotoxicol 1995; 16: 677-88.

7. Gladen BC, Rogan WJ, Hardy P, Thullen J, Tingelstad J, Tully M. Development after exposure to polychlorinated biphenyls and dichlorodiphenyl dichloroethene transplacentally and through human milk. J Pediatr 1988; 113: 991-5.

8. Jacobson JL, Jacobson SW, Humphrey HEB. Effect of in utero exposure to polychlorinated biphenyls and related contaminants on cognitive functioning in young children. J Pediatr 1990; 116: 38-45.

9. Sauer PJJ, Huisman M, Koopman-Esseboom, Morse DC, Smits-van Prooije AE, van de Berg KJ, et al. Effe of polychlorinated biphenyls (PCBs) and dioxins on growth and development. Hum Exper Toxicol 1994; 13 


\section{Steuerwald et al.}

900-6.

10. Brouwer A, Morse DC, Lans MC, Schuur AG, Murk AJ, Klasson-Wehler E, et al. Interactions of persistent environmental organohalogens with the thyroid hormone system: mechanisms and possible consequences fo animal and human health. Toxicol Ind Health 1998; 14: 59-84.

11. Hearn TL, Sgoutas SA, Hearn JA, Sgoutas DS. Polyunsaturated fatty acids and fat in fish flesh for selecting species for health benefits. J Food Sci 1987; 52: 1209-11.

12. Cappon C, Smith JC. Chemical form and distribution of mercury and selenium in edible seafood. J Anal Toxicol 1982; 6: 10-21.

13. Bjerve KS, Brubakk AM, Fougner KJ, Johnsen H, Midthjell K, Vik T. Omega-3 fatty acids: essential fatty acids with important biological effects, and serum phospholipid fatty acids as markers of dietary w3-fatty ac intake. Am J Clin Nutr 1993; 57: 801S-6S.

14. Bourre J-M, Dumont O, Piciotti M, Pascal G, Durand G. Polyunsaturated fatty acids of the n-3 serie and nervous system development. In Galli C, Simopoulos AP, eds. Dietary $\omega 3$ and $\omega 6$ fatty acids, biological effects and nutritional essentiality. New York, Plenum 1989, pp. 159-75.

15. Ganther HE, Goudie C, Sunde ML, Kopecky MJ, Wagner P. Selenium: relation to decreased toxicity of methylmercury added to diets containing tuna. Science 1972; 175: 1122-4.

16. Touwen BCL, Huisjes HJ, Jurgens-vdZee AD, Bierman-van Eendenburg MEC, Smrkovsky M, Olinga AA. Obstetrical condition and neonatal neurological morbidity. An analysis with the help of the optimality conce Early Hum Developm 1980; 4: 207-28.

17. Grandjean P, Weihe P, Jørgensen PJ, Clarkson T, Cernichiari E, Viderø T. Impact of maternal seafood diet fetal exposure to mercury, selenium, and lead. Arch Environ Health 1992; 47: 185-95. 


\section{Steuerwald et al.}

18. Prechtl HFR. The neurological examination of the full-term newborn infant, 2nd ed. Clinics in Developmen Medicine, No. 63. London: Heinemann, 1977.

19. Hadders-Algra M, Touwen BCL, Olinga AA, Huisjes HJ. Minor neurological dysfunction and behavioural development. A report from the Groningen perinatal project. Early Hum Developm 1985; 11: 221-9.

20. Pineau A, Piron M, Boiteau H-L, Etourneau M-J, Guillard O. Determination of total mercury in human hair samples by cold vapor atomic absorption spectrometry. J Anal Toxicol 1990; 14: 235-8.

21. Brock J, Burse VW, Ashley DL, Najam AR, Green VE, Korver MP, et al. An improved analysis for chlorinated pesticides and polychlorinated biphenyls (PCB's) in human and bovine sera using solid-phase extraction. J Anal Toxicol 1996; 20: 528-36.

22. Schade G, Heinzow B. Organochlorine pesticides and polychlorinated biphenyls in human milk of mothers living in Northern Germany: Current extent of contamination, time trend from 1986 to 1997, and factors tha influence the levels of contamination. Sci Total Environ 1998; 215: 31-9.

23. Grandjean P, Nielsen GD, Jørgensen PJ, Hørder M. Reference intervals for trace elements in blood: Significance of risk factors. Scand J Clin Lab Invest 1992; 52: 321-337.

24. Bjerve KS, Fischer S, Alme K. Alpha-linolenic acid deficiency in man: effect of ethyl linolenate on plasma and erythrocyte fatty acid composition and biosynthesis of prostanoids. Am J Clin Nutr 1987; 46: 570-6.

25. Grandjean P, Weihe P, Needham LL Burse VW, Patterson DG Jr, Sampson EJ, et al. Effect of a seafood die on mercury, selenium, arsenic, and PCBs and other organochlorines in human milk. Environ Res 1995; 71: 38.

26. Sørensen N, Murata K, Budtz-Jørgensen E, Weihe P, Grandjean P. Blood pressure and heart rate in 7-year-c children with prenatal exposure to methylmercury. Epidemiol 1999; 10: 370-5. 


\section{Steuerwald et al.}

27. Yamaguchi S, Matsumoto H, Kaku S, Tateishi M, Shiramizu M. Factors affecting the amount of mercury in human scalp hair. Am J Publ Health 1975; 65: 484-8.

28. Huisman M, Koopman-Esseboom C, Fidler V, Hadders-Algra M, van der Paauw CG, Tuinstra LGMT, et al Prenatal exposure to polychlorinated biphenyls and its effect on neonatal neurological development. Early Hum Dev 1995; 41: 111-27.

29. Bønaa KH, Bjerve KS, Nordøy A. Habitual fish consumption, plasma phospholipid fatty acids, and serum lipids: the Tromsø study. Am J Clin Nutr 1992; 55: 1126-34.

30. Al MDM, Badart-Smook A, v Houwelingen AC, Hasaart THM, Hornstra G. Fat intake of women during normal pregnancy: Relationship with maternal and neonatal essential fatty acid status. J Am Coll Nutr 1996 15: 49-55. 


\section{Steuerwald et al.}

Table I. Characteristics of the cohort of 182 newborns

Parameter

Outcome

Maternal age in years $($ mean $\pm S D)$

$28.0 \pm 5.8$

Previous births (none/one/at least two in \%)

$29.7 / 29.1 / 41.2$

Smoking during pregnancy (no/yes in \%)

$68.7 / 31.3$

Alcohol consumption during pregnancy (never/ever in \%)

$87.4 / 12.6$

Whale meat dinners per month (none/one/at least two in \%)

$39.9 / 25.3 / 34.8$

Whale blubber dinners per month (none/one/at least two in \%)

$47.2 / 18.5 / 34.3$

Fish dinners per week (none/one/two/at least three in \%)

$1.1 / 19.1 / 29.2 / 50.6$

Birth weight in $g($ mean \pm SD)

$3662 \pm 483$

Gestational age in weeks (mean \pm SD)

$39.6 \pm 1.2$

Sex of child (boy/girl in \%)

$51.1 / 48.9$

Age at examination in days (mean $\pm \mathrm{SD})$

$16.8 \pm 7.4$

Obstetric optimality score (mean \pm SD)

$58.0 \pm 3.8$ 


\section{Steuerwald et al.}

Table II. Biomarkers reflecting seafood contaminant exposures in 182 births and the association with maternal seafood dinner frequency during pregnancy and the neurological optimality score (NOS) of the infant

\begin{tabular}{|c|c|c|c|c|c|c|c|c|}
\hline & \multirow[b]{2}{*}{ Number } & \multirow{2}{*}{$\begin{array}{l}\text { Geometric } \\
\text { average }\end{array}$} & \multirow{2}{*}{$\begin{array}{c}\text { Interquartile } \\
\text { range }\end{array}$} & \multirow{2}{*}{$\begin{array}{l}\text { Total } \\
\text { range }\end{array}$} & \multirow[b]{2}{*}{ Fish } & \multicolumn{3}{|c|}{ Correlation $^{\mathrm{a}}$} \\
\hline & & & & & & Whale & Blubber & NOS \\
\hline Cord blood $(\mu \mathrm{g} / \mathrm{l})$ & 163 & 20.4 & $11.8-40.0$ & $1.90-102$ & 0.14 & $0.47 * * *$ & $0.26^{* *}$ & $-0.16^{*}$ \\
\hline Cord serum $(\mu \mathrm{g} / \mathrm{l})$ & 174 & 2.54 & $1.65-3.66$ & $0.70-8.74$ & 0.13 & $0.44 * * *$ & $0.20^{* *}$ & -0.12 \\
\hline Mat. hair $(\mu \mathrm{g} / \mathrm{g})$ & 144 & 4.08 & $2.45-7.35$ & $0.36-16.3$ & $0.24^{* *}$ & $0.46^{* * *}$ & $0.22 * *$ & -0.10 \\
\hline \multicolumn{9}{|l|}{$\Sigma \mathrm{PCB}$} \\
\hline Mat. serum $(\mu \mathrm{g} / \mathrm{g})$ & ) 173 & 1.12 & $0.62-1.87$ & $0.04-18.4$ & $0.18^{*}$ & $0.27^{* * *}$ & $0.40 * * *$ & 0.03 \\
\hline Milk $(\mu \mathrm{g} / \mathrm{g})$ & 168 & 1.52 & $0.87-2.52$ & $0.07-18.5$ & 0.12 & $0.22 * *$ & $0.36^{* *}$ & -0.03 \\
\hline \multicolumn{9}{|l|}{$p, p^{\prime}-\mathrm{DDE}$} \\
\hline Mat. serum $(\mu \mathrm{g} / \mathrm{g})$ & ) 173 & 0.72 & $0.40-1.21$ & $0.18-8.0$ & $0.19^{* *}$ & $0.25^{* *}$ & $0.44 * * *$ & 0.02 \\
\hline Milk $(\mu \mathrm{g} / \mathrm{g})$ & 168 & 0.87 & $0.49-1.55$ & $0.05-13.7$ & 0.15 & $0.24 * *$ & $0.46^{* * *}$ & -0.01 \\
\hline
\end{tabular}

${ }^{a}$ Spearman's correlation coefficient

'p $<0.05 ; * * \mathrm{p}<0.01 ; * * \mathrm{p}<0.001$ 


\section{Steuerwald et al.}

Table III. Concentrations of essential nutrients in cord serum, as related to maternal seafood diet during pregnancy and concentrations of toxicants from seafood, and the neurological optimality score (NOS) of the infant.

Correlation $^{\mathrm{a}}$

Mean (s.d.) Fish Whale Blubber Mercury $\Sigma$ PCB NOS

Fatty acids (\% of total in phospholipids)

$\begin{array}{llllllll}\text { Arachidonic }(\mathrm{C} 20: 4 \omega 6) & 16.44(1.64) & -0.02 & 0.02 & 0.10 & 0.06 & -0.03 & 0.14\end{array}$

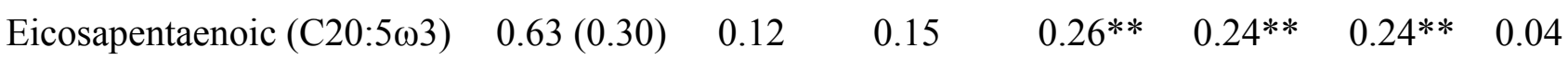

$\begin{array}{llllllll}\text { Docosahexaenoic }(\mathrm{C} 22: 6 \omega 3) & 8.87(1.66) & 0.01 & 0.18^{*} & 0.10 & 0.01 & 0.01 & 0.08\end{array}$

$\begin{array}{llllllll}\text { Total } \omega 3 & 10.8(1.9) & 0.08 & 0.13 & 0.09 & 0.11 & 0.19^{*} & 0.08\end{array}$

$\begin{array}{llllllll}\text { Selenium }(\mu \mathrm{g} / \mathrm{l} \text { blood }) & 103.4(14.2) & 0.25^{* *} & 0.16 & 0.21^{*} & 0.27^{* *} & 0.23^{* *} & 0.06\end{array}$

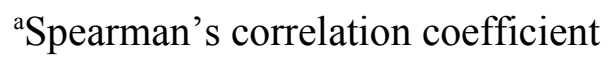

${ }^{*} \mathrm{p}<0.05 ; * * \mathrm{p}<0.01 ; * * * \mathrm{p}<0.001$ 


\section{Steuerwald et al.}

Figure legend:

Fig. 1. Neurological optimality score (mean \pm s.e.m.) in relation to cord-blood mercury concentrations in approximate quartile groups.

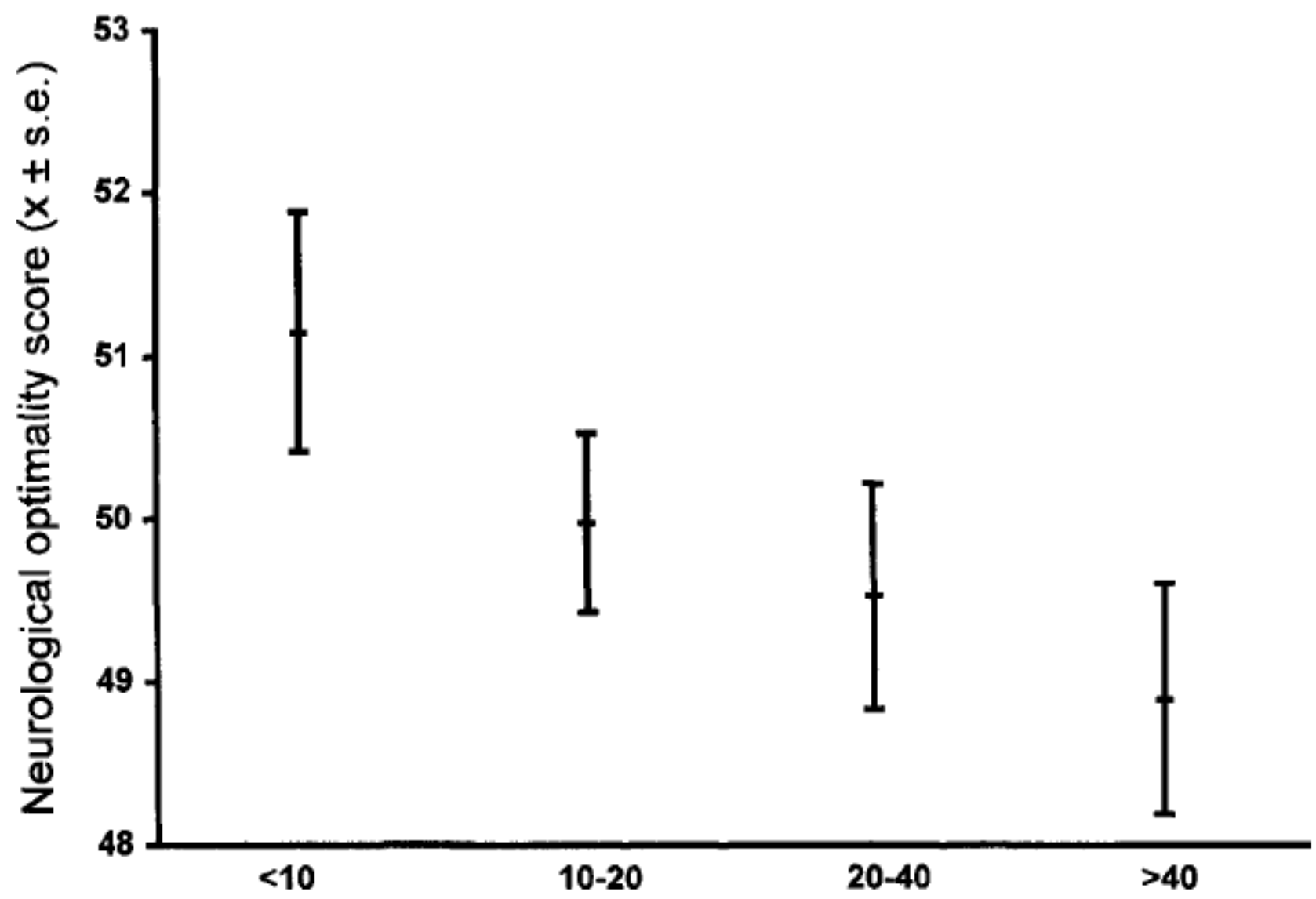

